\title{
Genetic alterations in a primary medullary thyroid carcinoma and its lymph node metastasis in a patient with 15 years follow-up
}

\author{
Beatriz González-Yebra ${ }^{1,3}$, Raúl Peralta1,5, Ana Lilia González², Marco Antonio Ayala-Garcia²,
} María E Medrano Ortiz de Zarate $^{4}$ and Mauricio Salcedo ${ }^{5^{*}}$

\begin{abstract}
Background: Association between DNA alterations and clinical parameters as recurrence, survival or prognosis has been found in a variety of tumors. A clear association between Medullary Thyroid Carcinoma (MTC) and RET oncogene mutation has been accepted. Specifically M918T RET mutation represents the main genetic event in most cases of sporadic MTC (SMTC) and limited chromosomal alterations analyses have been performed.

Methods: In the present work, a comparative genomic hybridization (CGH) study was performed using DNA from a primary tumor in a M918T RET mutation-positive SMTC patient and from its lymph node metastasis to investigate additional genetic alterations. We studied a patient with 15 years of follow-up and persistence of disease, confirmed by periodical elevated serum calcitonin (CT) levels.

Results: Only 3 chromosomal imbalances were identified in the primary tumor, gain of 18p, and loss of $6 p$ and $16 p$ region, whereas 25 chromosomal imbalances were identified in the metastasis ( 9 gains and 16 losses).

Conclusion: The chromosomal changes 6p-, 16p-, 18p + could determine in part the oncogenic phenotype in the primary M918T RET positive tumor and probably related to persistence of high serum CT levels in this patient. The additional chromosomal changes observed could be related to the metastasis phenotype. We suggest that some genes mapped at 6p, 16p and 18p chromosomal regions, could act as genes associated to cancer and could be related to persistent SMTC and good prognosis.
\end{abstract}

Virtual slides: The virtual slide(s) for this article can be found here: http://www.diagnosticpathology.diagnomx.eu/ vs/1720753793691097

Keywords: Sporadic MTC, M918T RET mutation, Chromosomal alterations

\section{Background}

Medullary thyroid carcinoma (MTC) is a neuroendocrine tumor arising from the parafollicular cells of the thyroid gland and approximately $75 \%$ of cases are sporadic type (SMTC) [1]. Survival rate is closely related to clinical parameters such as tumor stage, age of diagnosis, elevated postoperative serum calcitonin (CT) levels, and recurrence of the tumor [2]. Other parameters that

\footnotetext{
*Correspondence: maosal89@yahoo.com

${ }^{5}$ Laboratorio de Oncología Genómica, Unidad de Investigación Médica en Enfermedades Oncológicas, Hospital de Oncología, CMN SXXI-IMSS, Av.

Cuauhtémoc 330, Col. Doctores, México, DF 06720, Mexico

Full list of author information is available at the end of the article
}

contribute to survival rates include lymph node metastasis, tumor size $>4 \mathrm{~cm}$, extrathyroid and extranodal tumor extensions [3]. Thus, patients who are treated in the earlier stages of the disease have a better prognosis. Patients with tumors that are limited to the thyroid (stage I) have a survival rate of $95 \%$ at 10 and 20 years. Patients with advanced tumors, stages III and IV, have a survival rate of $55 \%$ and $28 \%$ at 10 and 20 years, respectively. Frequently, persistence of the disease is associated with elevated postoperative serum CT levels and persistence of the tumor increased over time. However, $30 \%$ of SMTC patients continued to show only elevated CT

\section{Biomed Central}

(c) 2012 González-Yebra et al.; licensee BioMed Central Ltd. This is an Open Access article distributed under the terms of the Creative Commons Attribution License (http://creativecommons.org/licenses/by/2.0), which permits unrestricted use, distribution, and reproduction in any medium, provided the original work is properly cited. 
levels without additional clinical evidence of the disease (persistence), even after 15 years [2,3].

At genetic level, the first event in SMTC tumorigenesis is thought to be the M918T RET mutation (ATG $\rightarrow$ ACG) [4-11]. This mutation is associated with 30-66\% of SMTC and 95\% of Multiple Endocrine Neoplasia type 2B [4-9]. This mutation has been associated with a poor prognosis, tumor recurrence and the presence of lymph node metastases [10-13].

Comparative genomic hybridization (CGH) studies have been widely applied to cancer research $[14,15]$. CGH analysis has been performed in SMTCs showing common chromosomal alterations as loss in 1p, 3q, 4q, 13q, 17, 22q and gains in 11q, 12p, 14q, 19q and 22q (Table 1). Some of these imbalances have been related to specific clinical behavior such as the clinical outcome [16].

In order to know which chromosomal imbalances occur in a primary SMTC harboring a M918T RET mutation and its lymph node metastasis in a patient with 15 years of clinical follow-up, a CGH analysis was performed.

\section{Case presentation}

In this study, we report a case of a 70 year-old female who was diagnosed with SMTC 15 years ago. A total resection of the thyroid gland and a resection of the right lymph nodes in the neck were performed at age 55. At the time of surgery, a unilateral tumor was detected in the right lobe of the thyroid. Histopathological findings confirmed a $7.5 \times 3.5 \times 2 \mathrm{~cm}$ tumor (T2) with extraglandular extension, 8/17 positive lymph nodes metastases (N1b) and no distant metastases (M0) were found. According to TNM classification, this patient was diagnosed as MTC stage III. One year later, the patient presented with persistently high serum CT levels $(2,400 \mathrm{pg} / \mathrm{mL})$. During a second surgery, a left lymph nodes resection was performed and histopathological analysis confirmed the presence of several lymph node metastases (10/49). At present, the patient is alive and has persistent disease, confirmed by periodical elevated serum CT levels $(3,193 \mathrm{pg} / \mathrm{mL}$ at the latest screening).
Molecular diagnostic testing confirmed the presence of the M918T RET mutation in the tumor and lymph node metastases previously. Interestingly, our case study demonstrate that despite the mutation and the presence of several lymph nodes metastases, the patient experienced a good survival rate (15 years after surgery) and still alive. Then, we focused in search of genetic DNA alterations by $\mathrm{CGH}$ that could be important in the favorable prognosis of this patient. The CGH procedure was performed using reagents and kits from Vysis Inc. (Downers Grove, IL), following the manufacturer's instructions. Tumoral DNA was labeled using the CGH nick translation kit and the hybridization mixture was prepared according to the $\mathrm{CGH}$ reagent kit, consisting of $200 \mathrm{ng}$ of spectrum-green labeled tumoral DNA, $200 \mathrm{ng}$ of spectrum-red labeled normal male reference DNA and $20 \mu \mathrm{g}$ of human Cot-1 DNA. Hybridization was performed over 3 days at $37{ }^{\circ} \mathrm{C}$ on normal male metaphase spreads (Vysis, Downers Grove, IL). Digital images were collected using the Smart Capture (Vysis) software with a charged coupled device camera mounted on an epifluorescence microscope. In the primary tumor, the chromosomal alterations detected were losses in $6 \mathrm{p}$ and $16 \mathrm{p}$ and gain in $18 \mathrm{p}$, while 25 chromosomal alterations were detected in the lymph node metastasis with more losses than gains (Table 1).

\section{Discussion}

Cancer progression and the metastasis result from the accumulation of multiple genetic changes. In the current study, DNA from a primary tumor and a lymph node metastasis of a persistent SMTC patient, harboring the M918T RET mutation, was subjected to CGH analysis to evaluate additional genetic changes. This analysis demonstrated differences in genetic changes between the primary tumor and the metastasis, 3 genetic changes vs. 25 genetic changes, respectively. Interestingly, DNA losses were more common than gains, and a complete deletion of chromosomes 16, 17, 19, and 20 were observed in the metastasis (Figure 1). In contrast, a high

Table 1 Chromosomal alterations reported in carcinoma tissues from SMTC using CGH analysis

\begin{tabular}{|c|c|c|c|c|c|}
\hline Tissue & n & Ret mut & Gains & Losses & Reference \\
\hline SMTC primary tumor & 10 & Unknown & $1 q, 6,7 p, 11 q, 21 q$ & $1 p, 3 q, 3, \mathbf{1 3}, 18 p, 18 q, 22$ & Hemmer et al., 1999 [18] \\
\hline SMTC primary tumor & 9 & M918T & $1 p, 5 p, 7 q, 8 q, 9 q, \mathbf{1 1 q}, 16,19 p, 19 q, \mathbf{2 2 q}$ & $1 \mathbf{p}, 2 q, 3 q, 3,4 q, 9 p+q, 10,12 p, 12 q, 13 q$ & Frisk et al., 2001 [16] \\
\hline SMTC primary tumor & 12 & M918T & $6 p, 6,7,12 p, 14 q, 15 q, 16,19, x$ & $\begin{array}{l}\mathbf{1 p}, 3 \mathbf{q}, \mathbf{3}, \mathbf{4 q}, 5 \mathbf{q}, 9,11, \mathbf{1 3 q}, 16 p, 16 \\
17 p, \mathbf{1 7}, 19,20 q, 20, \mathbf{2 2} \mathbf{q}, \mathbf{X}\end{array}$ & Marsh et al., 2003 [19] \\
\hline SMTC primary tumor & 1 & M918T & $18 p$ & $6 p, 16 p$ & Present case \\
\hline SMTC metastasis & 1 & M918T & $6,14 q$ & $x$ & Marsh et al., 2003 [19] \\
\hline SMTC metastasis & 1 & M918T & $\begin{array}{l}2 q, 3 q, 4 p+q, 5 p+q, 6 q, 8 q \\
12 p+q, 13 q, x q\end{array}$ & $\begin{array}{l}1 p, 1 q, 6 p, 8 p, 8 q, 9 q, 10 p, 10 q, 11 q \\
12 q, 15 q, 16,17,19,20 \text {, and } 22 q\end{array}$ & Present case \\
\hline
\end{tabular}

Note: $\mathrm{n}$ : number of cases studied; Ret mut: type of RET mutation; M918T: codon 918 (Met- > Thr). In bold letter the most common CGH gains and losses. Bold font indicates most common CGH imbalances reported by author. 


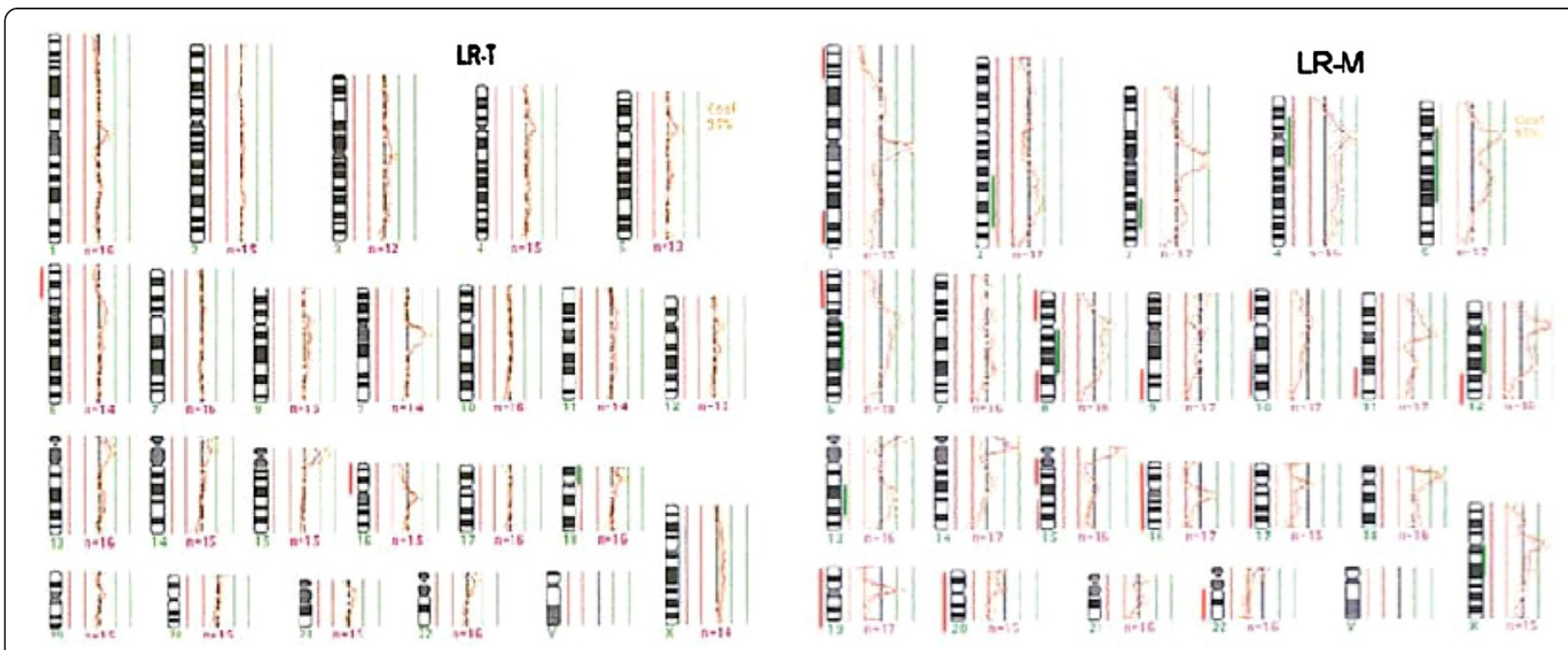

Figure 1 CGH analysis profile from SMTC tissues: A) Primary tumor, B) Metastasis. Red lines to the left of chromosomes represent losses (CGH fluorescence ratios $<0.80$ ), green lines to the right of chromosomes represent gains (ratio $>1.20$ ). Abbreviations: LR-T: Primary tumor, LR-M: Metastasis.

number of chromosomal alterations in lymph nodes metastasis have been previously found [16]. These findings could indicate a complex pattern of DNA alterations related to metastasis in this patient. It is important to note that the chromosomal alterations observed in the primary tumor are also present in its metastasis, indicating that those changes could be associated to clonal origin. This is also supported by the presence of the M918T RET mutation in the metastasis.

To date, only few studies have analyzed chromosomal imbalances in primary tissue of SMTC [16-18]. Our data support previous results indicating that the SMTC could be characterized by more DNA losses than gains $[16,18]$. One report had suggested that the SMTC harboring the M918T RET mutation have a higher degree of chromosomal instability and usually display a higher number of DNA alterations [16]. However, the fewer number of DNA alterations present in the primary tumor of our patient could be related to persistence or good prognosis. If this is true, the low number of specific DNA alterations in the primary tumor could be of prognostic value in SMTC patients.

In other study, the loss of chromosomes 1p, 3q 13q and 22q were detected in some SMTC patients with M918T RET mutation. However, the chromosomal alterations in the metastasis described in the present study, are partially similar than those described for the primary tumor in other reports (Table 1). Therefore, it is possible that some of these DNA alterations could be associated with clinical parameters such as prognosis, tumor size, and metastasis. For instance, gains of chromosome 19 and chromosome 11q12 were observed in patients whom died of the disease, and they also harbored the M918T mutation [16]. It is clear that heterogeneity in chromosomal alterations is present in SMTCs. Several authors have suggested that these CGH imbalances could contribute to outcome or prognosis and that those genetic regions may contain genes associated to the development of SMTC [16-19]. An overexpression of genes involved in proliferation and invasion such as PTN (7q33); ESM1 (5q11), and CEACAM (19q13) could also characterize an aggressive SMTC [20]. Thus, our results are supported by these previous findings indicating that chromosomal changes at $6 \mathrm{p}, 16 \mathrm{p}$ and 18p observed in the SMTC, could not be associated with an aggressive prognosis. On the other hand, it is widely known that the M918T RET mutation is associated with poor prognosis and persistence of the disease [9-12]. According to our results, the patient harboring the M918T RET mutation failed in the poor prognosis, however, she had persistence SMTC. In this case we hypothesized that our patient harboring the RET mutation (aggressive mutation) could be subjected to an epigenetic mechanism as methylation (for instance, an imprinted mutated allele) allowing the long survival (good prognosis). Based on our results, we suggest that: $6 \mathrm{p}, 16 \mathrm{p}$, and $18 \mathrm{p}$ regions could contain genes associated to cancer that are common in human cancer genome $[21,22]$ and the loss or gain could be associated to good prognosis and long-term survival. More detailed analyses are needed to support the existence of good prognostic markers in chromosomal regions that contain imbalances. To avoid a limited significance about genetic alterations in persistence SMTC harboring M918T RET mutation patients should be necessary to analyze more of these kind of patients. 


\section{Conclusion}

In summary, the chromosomal alterations in SMTC are quite heterogeneous; however, the number and specific DNA alterations could mark our patient's prognosis even when harbors the M918T RET mutation. Losses in 6p and 16p, and gain in 18p could be related to a favorable prognostic outcome, persist disease and high serum CT levels in SMTC.

\section{Consent}

Written informed consent was obtained from the patient for publication of this case report and any accompanying images. A copy of the written consent is available for review by the Editor-in-Chief of this Journal.

\section{Competing interest}

The authors declare that they have no competing interests.

\section{Authors' contributions}

BG and MS conceived the study, participated in its design and coordination and helped to draft the manuscript. RP, MA, MM and ALG carried out the molecular studies and drafted the manuscript. All authors read and approved the final manuscript

\section{Acknowledgements}

We wish to thank Dr. M. Hermsen for his help with the methodology and his review of the manuscript. This work was partially supported by grants 69719, 87244 from CONACYT, Mexico.

\section{Author details}

'Departamento de Medicina y Nutrición, División de Ciencias de la Salud, Campus León, Universidad de Guanajuato, Guanajuato, Mexico.

${ }^{2}$ Departamento de Ciencias Aplicadas al Trabajo, División de Ciencias de la Salud, Campus León, Universidad de Guanajuato, Guanajuato, Mexico. ${ }_{3}^{3}$ Hospital Regional de Alta Especialidad del Bajío, León, Guanajuato, México. ${ }^{4}$ Departamento de Endocrinología, Hospital de Oncología, Centro Médico Nacional Siglo XXI-IMSS, México, DF, México. ${ }^{5}$ Laboratorio de Oncología Genómica, Unidad de Investigación Médica en Enfermedades Oncológicas, Hospital de Oncología, CMN SXXI-IMSS, Av. Cuauhtémoc 330, Col. Doctores, México, DF 06720, Mexico.

Received: 7 March 2012 Accepted: 13 May 2012

Published: 7 June 2012

\section{References}

1. Randolph GW, Maniar D: Medullary carcinoma of the thyroid. Cancer Control 2000, 7:253-261

2. Girelli ME, Nacamulli D, Pelizzo MR, De Vido D, Mian C, Piccolo M, Busnardo B: Medullary thyroid carcinoma: clinical features and long-term follow-up of seventy-eight patients treated between 1969 and 1986. Thyroid 1998, 8:517-523.

3. Ito Y, Miyauchi A, Yabuta T, Fukushima M, Inoue H, Tomoda C, Uruno T, Kihara M, Higashiyama T, Takamura Y, Miya A, Kobayashi K, Matsuzuka F: Alternative surgical strategies and favorable outcomes in patients with medullary thyroid carcinoma in Japan: experience of a single institution. World J Surg 2009, 33(1):58-66.

4. González B, Salcedo M, Medrano ME, Mantilla A, Quiñonez G, BenítezBibriesca L, Rodríguez-Cuevas S, Cabrera L, de León B, Altamirano N, Tapia J, Dawson B: RET oncogene mutations in medullary thyroid carcinoma in Mexican families. Arch Med Res 2003, 34(1):41-49.

5. Hofstra RM, Landsvater RM, Ceccherini I, Stulp RP, Stelwagen T, Luo Y, Pasini B, Höppener JW, van Amstel HK, Romeo G: A mutation in the RET protooncogene associated with multiple endocrine neoplasia type $2 \mathrm{~B}$ and sporadic medullary thyroid carcinoma. Nature 1994, 367:375-376,

6. Eng C, Smith DP, Mulligan LM, Nagai MA, Healey CS, Ponder MA, Gardner E, Scheumann GF, Jackson CE, Tunnacliffe A: Point mutation within the tyrosine kinase domain of the RET proto-oncogene in multiple endocrine neoplasia type $2 \mathrm{~B}$ and related sporadic tumors. Hum $\mathrm{Mol}$ Genet 1994, 3:237-241.

7. Zedenius J, Wallin G, Hamberger B, Nordenskjöld M, Weber G, Larsson C Somatic and MEN2A de novo mutations identified in the RET protooncogene by screening of sporadic MTC:s. Hum Mol Genet 1994, 3:1259-1262.

8. Eng C, Mulligan LM, Smith DP, Healey CS, Frilling A, Raue F, Neumann HP, Pfragner R, Behmel A, Lorenzo MJ: Mutation of the RET protooncogene in sporadic medullary thyroid carcinoma. Genes Chromosomes Cancer 1995, $12: 209-212$

9. Scurinni C, Quadro L, Fattoruso O, Verga U, Libroia A, Lupoli G, Cascone E, Marzano L, Paracchi S, Busnardo B, Girelli ME, Bellastella A, Colantuoni V: Germline and somatic mutations of the RET proto-oncogene in apparently sporadic medullary thyroid carcinomas. Mol Cell Endocrinol 1998, 137:51-57

10. Zedenius J, Larsson C, Bergholm U, Bovée J, Svensson A, Hallengren B, Grimelius L, Bäckdahl M, Weber G, Wallin G: Mutations of codon 918 in the RET proto-oncogene correlate to poor prognosis in sporadic medullary thyroid carcinomas. J Clin Endocrinol Metabol 1995, 80:3088-3090.

11. Schilling T, Bürk J, Sinn HP, Clemens A, Otto HF, Höppner W, Herfarth C, Ziegler R, Schwab M, Raue F: Prognostic value of codon 918 (ATG $\rightarrow$ ACG) RET proto-oncogene mutations in sporadic medullary thyroid carcinoma. Int J Cancer 2001, 95:62-66.

12. Romei C, Elisei R, Pinchera A, Ceccherini I, Molinaro E, Mancusi F, Martino E, Romeo G, Pacini F: Somatic mutations of the RET protooncogene in sporadic medullary thyroid carcinoma are not restricted to exon 16 and are associated with tumor recurrence. J Clin Endocrinol Metabol 1996, 81:1619-1622.

13. Elisei R, Cosci B, Romei C, Bottici V, Renzini G, Molinaro E, Agate L, Vivaldi A, Faviana P, Basolo F, Miccoli P, Berti P, Pacini F, Pinchera A: Prognostic significance of somatic RET oncogene mutations in sporadic medullary thyroid cancer: a 10-year follow-up study. J Clin Endocrinol Metabol 2008, 93:682-687.

14. Pinkel D, Albertson DG: Comparative genomic hybridization. Annu Rev Genomics Hum Genet 2005, 6:331-354.

15. Weiss MM, Hermsen MA, Meijer GA, van Grieken NC, Baak JP, Kuipers E, van Diest PJ: Comparative genomic hybridization. Mol Pathol 1999, 52:243-251.

16. Frisk T, Zedenius J, Lundberg J, Wallin G, Kytölä S, Larsson C: CGH alterations in medullary thyroid carcinomas in relation to the RET M918T mutation and clinical outcome. Int J Oncol 2001, 18:1219-1225.

17. Ye L, Santarpia L, Cote GJ, El-Naggar AK, Gagel RF: High resolution arraycomparative genomic hybridization profiling reveals deoxyribonucleic acid copy number alterations associated with medullary thyroid carcinoma. J Clin Endocrinol Metab 2008, 93:4367-4372.

18. Hemmer S, Wasenius VM, Knuutila S, Franssila K, Joensuu H: DNA copy number changes in thyroid carcinoma. Am J Surg Pathol 1999, 154:1539-1547.

19. Marsh DJ, Theodosopoulos G, Martin-Schulte K, Richardson AL, Philips J, Röher HD, Delbridge L, Robinson BG: Genome-wide copy number imbalances identified in familial and sporadic medullary thyroid carcinoma. J Clin Endocrinol Metab 2003, 88:1866-1872.

20. Ameur N, Lacroix L, Roucan S, Roux V, Broutin S, Talbot M, Dupuy C, Caillou B, Schlumberger M, Bidart JM: Aggressive inherited and sporadic medullary thyroid carcinomas display similar oncogenic pathways. Endocr Relat Cancer 2009, 16:1261-1272.

21. Santarius T, Shipley J, Brewer D, Stratton MR, Cooper CS: A census of amplified and overexpressed human cancer genes. Nat Rev Cancer 2010, 10:59-64.

22. Knuutila S, Björkqvist AM, Autio K, Tarkkanen M, Wolf M, Monni O, Szymanska J, Larramendy ML, Tapper J, Pere H, El-Rifai W, Hemmer S, Wasenius VM, Vidgren V, Zhu Y: DNA copy number amplification in human neoplasm. Am J Pathol 1998, 152:1107-1123.

doi:10.1186/1746-1596-7-63

Cite this article as: González-Yebra et al:: Genetic alterations in a primary medullary thyroid carcinoma and its lymph node metastasis in a patient with 15 years follow-up. Diagnostic Pathology 2012 7:63. 